\title{
Guidelines
}

\section{Clube Português do Pâncreas Recommendations for Chronic Pancreatitis: Medical, Endoscopic, and Surgical Treatment (Part II)}

\author{
Eduardo Rodrigues-Pinto $^{a} \quad$ Ana Caldeira $^{b}$ João Bruno Soares ${ }^{c}$ \\ Teresa Antunes $^{d}$ Joana Rita Carvalho ${ }^{d}$ José Costa-Maia ${ }^{e}$ Pedro Oliveira ${ }^{f}$ \\ Richard Azevedo $^{b}$ Rodrigo Liberal ${ }^{a}$ Tiago Bouça Machado ${ }^{\mathrm{e}}$ \\ Vitor Magno-Pereirag Pedro Moutinho-Ribeiro ${ }^{a}$ \\ ${ }^{a}$ Gastroenterology Department, Centro Hospitalar de São João, Porto, Portugal; b Gastroenterology Department, \\ Hospital Amato Lusitano, Castelo Branco, Portugal; ' CGastroenterology Department, Hospital de Braga, Braga, \\ Portugal; ${ }^{d}$ Gastroenterology Department, Hospital de Santa Maria, Centro Hospitalar Lisboa Norte, Lisbon, Portugal;

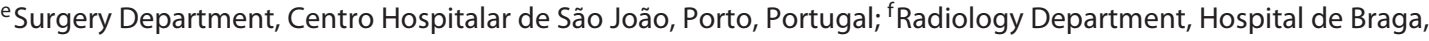 \\ Braga, Portugal; ${ }^{9}$ Gastroenterology Department, Hospital Central do Funchal, Funchal, Portugal
}

\section{Keywords}

Chronic pancreatitis · Medical treatment · Endoscopy · Surgery

\section{Abstract}

Chronic pancreatitis (CP) is a complex disease that should be treated by experienced teams of gastroenterologists, radiologists, surgeons, and nutritionists in a multidisciplinary environment. Medical treatment includes lifestyle modification, nutrition, exocrine and endocrine pancreatic insufficiency correction, and pain management. Up to $60 \%$ of patients will ultimately require some type of endoscopic or surgical intervention for treatment. However, regardless of the modality, they are often ineffective unless smoking and alcohol cessation is achieved. Surgery retains a major role in the treatment of CP patients with intractable chronic pain or

This is part Il of the Clube Português do Pâncreas Recommendations for Chronic Pancreatitis. For part I, see GE Port J Gastroenterol 2019, Doi 10.1159/000497388.

\section{KARGER}

E-Mail karger@karger.com www.karger.com/pjg (c) 2019 Sociedade Portuguesa de Gastrenterologia Published by S. Karger AG, Basel

Karger

Upen access

This article is licensed under the Creative Commons AttributionNonCommercial-NoDerivatives 4.0 International License (CC BYNC-ND) (http://www.karger.com/Services/OpenAccessLicense) Usage and distribution for commercial purposes as well as any distribution of modified material requires written permission. suspected pancreatic mass. For other complications like biliary or gastroduodenal obstruction, pseudocyst drainage can be performed endoscopically. The recommendations for CP were developed by Clube Português do Pâncreas (CPP), based on literature review to answer predefined topics, subsequently discussed and approved by all members of CPP. Recommendations are separated in two parts: "chronic pancreatitis etiology, natural history, and diagnosis," and "chronic pancreatitis medical, endoscopic, and surgical treatment." This abstract pertains to part II.

(C) 2019 Sociedade Portuguesa de Gastrenterologia Published by S. Karger AG, Basel

\section{Recomendações do Clube Português do Pâncreas sobre Pancreatite Crónica: Tratamento Médico, Endoscópico e Cirúrgico (Parte II)}

Palavras-Chave

Pancreatite crónica · Tratamento médico - Endoscopia . Cirurgia
Pedro Moutinho-Ribeiro, MD

Gastroenterology Department, Centro Hospitalar São João

Al. Prof. Hernâni Monteiro

PT-4200-319 Porto (Portugal)

E-Mail pmoutinhoribeiro@gmail.com 


\section{Resumo}

A pancreatite crónica (PC) é uma doença complexa que deve ser tratada por equipas multidisciplinares experientes de gastrenterologistas, radiologistas, cirurgiões e nutricionistas. O tratamento médico inclui modificação do estilo de vida, nutrição, correção das insuficiências pancreáticas endócrina e exócrina e controle da dor. Até $60 \%$ dos doentes podem necessitar de algum tipo de terapêutica endoscópica ou cirúrgica. No entanto, independentemente da modalidade, elas serão ineficazes, se não se alcançar cessação tabágica e etílica. A cirurgia desempenha um papel importante no tratamento dos doentes com dor crónica intratável ou lesões pancreáticas suspeitas. Outras complicações como obstrução biliar, gastroduodenal, ou drenagem de pseudocistos podem ser tratadas endoscopicamente. As recomendações sobre PC foram desenvolvidas pelo Clube Português do Pâncreas (CPP), com base numa revisão da literatura para responder a questões predefinidas, posteriormente discutidos e aprovados por todos os membros do CPP. As recomendações encontram-se separadas em duas partes: "etiologia da pancreatite crónica, história natural e diagnóstico" e "tratamento médico, endoscópico e cirúrgico da pancreatite crónica." Este resumo corresponde à parte II.

(C) 2019 Sociedade Portuguesa de Gastrenterologia Publicado por S. Karger AG, Basel

\section{Introduction}

This paper refers to part II of Clube Português do Pâncreas (CPP) recommendations for chronic pancreatitis (CP) management. The recommendations were initially based on literature review to answer predefined topics, subsequently discussed and approved by all members of CPP.

\section{Statement}

$\mathrm{CP}$ requires several treatments (Fig. 1). Pain management should be dealt with multidisciplinarily, with the several available therapeutic measures including nutrition, lifestyle modifications, pancreatic enzyme replacement therapy (PERT), and analgesics. CPP recommends alcohol and tobacco abstinence, a normal polyfractionated diet, and PERT. Analgesia should start with paracetamol. If unresponsive, tramadol is recommended and/ or combination with pregabalin. Nortriptyline is a useful adjuvant and, if necessary, analgesia may escalate to strong opioids. Patients with pancreatic exocrine insufficiency (PEI) should start PERT and titrate the dose (with a proton pump inhibitor [PPI]) until symptom res- olution and normalization of nutritional status. Serum levels of vitamins $A, D, E, K$, and $B_{12}$ and secondarily calcium, magnesium, zinc, thiamine, and folic acid need to be evaluated. All patients should undergo an annual fasting glucose and $\mathrm{HbAlc}$ and be treated accordingly if endocrine insufficiency is diagnosed. Mild hyperglycemia in the initial phases of disease may be controlled with oral hypoglycemic agents; however, in advanced disease, insulin is the only effective therapy.

Surgery retains a major role in the treatment of CP patients with intractable chronic pain or suspected pancreatic mass. Pancreatoduodenectomy (PDD) and distal pancreatic resections should be the treatment of choice in cases where malignancy is suspected. However, endoscopic therapy should be considered as a first-line therapy for painful uncomplicated CP, since it is less invasive and may reduce or delay the need for surgery. If clinical success can be obtained with $\leq 5$ endoscopic interventions, the patient will probably achieve a long-term favorable outcome. The best candidates for successful treatment of painful CP are patients with distal obstruction of the main pancreatic duct (MPD) (single stone and/or single stricture in the head of the pancreas) and in the early stages of the disease. For other complications like biliary or gastroduodenal obstruction, pseudocyst drainage should also be performed endoscopically.

\section{Medical Treatment}

\section{Lifestyle Modification}

Abstinence from alcohol and tobacco are essential and mandatory components of medical guidance. Alcohol abstinence has a significant effect on endocrine pancreatic function [1]. Although there is a maintained deterioration in pancreatic exocrine function, both in patients who stop alcohol and in those who continue, the process is significantly less marked in patients who stop drinking [2]. Alcohol intake, even less than $50 \mathrm{~g} /$ day, induces earlier disease characterized by more frequent severe pain, pancreatic calcifications, and complications. Intake of large amounts of alcohol ( $\geq 50 \mathrm{~g} /$ day) accelerates calcification and reduces life expectancy [3].

Tobacco smoking is an independent risk factor for pancreatitis and accelerates the course of CP in a dosedependent way, apart from alcohol intake [4-6]. Even for idiopathic CP, smoking has been extensively demonstrated as an independent risk factor [7]. Tobacco cessation appears to be associated with even more benefits as it also reduces the risk of secondary pancreatic carcinoma. The 


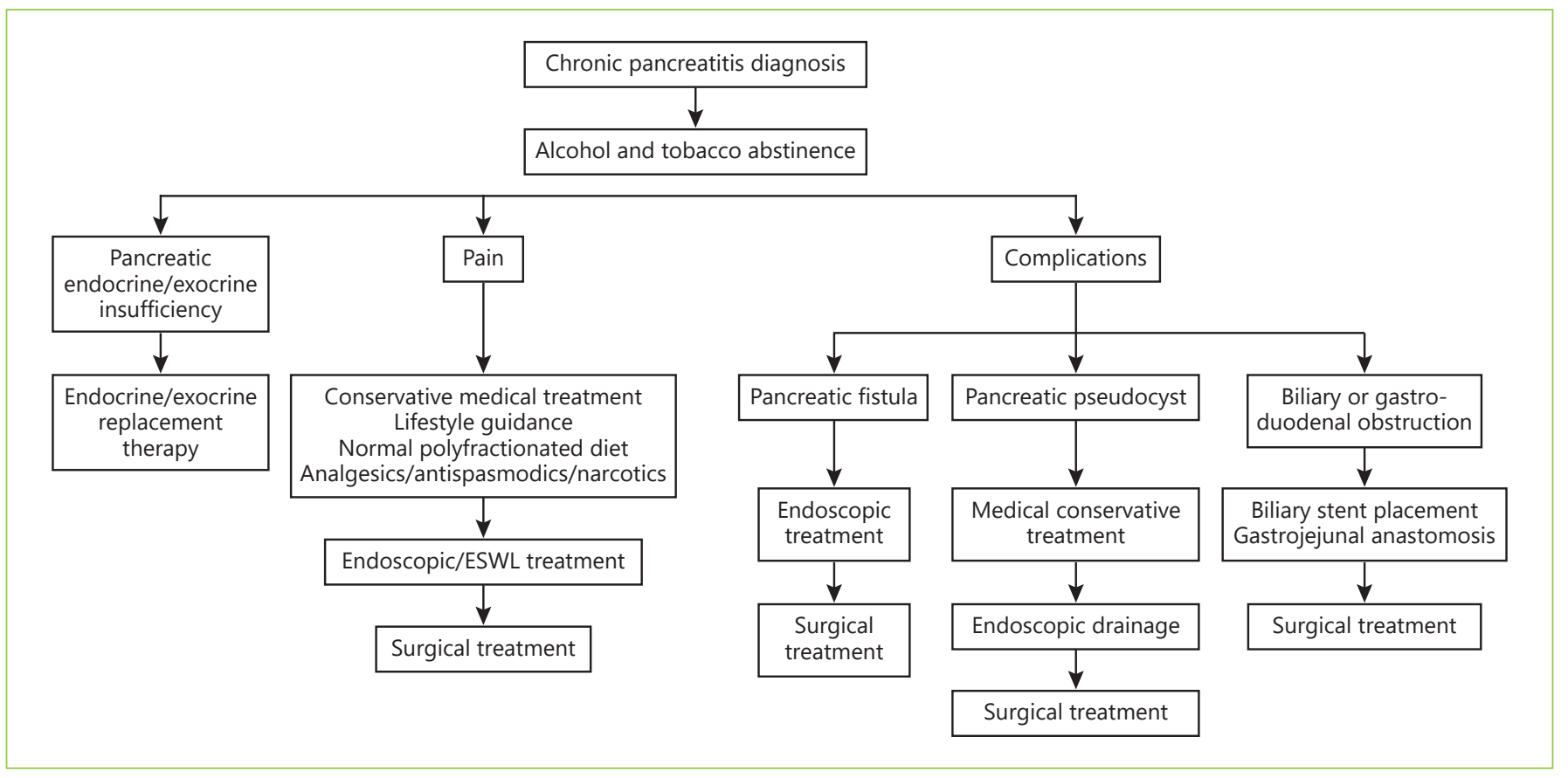

Fig. 1. Algorithm approach to therapy of chronic pancreatitis.

International Pancreatic Cancer Case-Control Consortium demonstrated an odds ratio (OR) for pancreatic cancer of 1.2 for former smokers and 2.2 for current smokers, with a significant increasing trend in risk with increasing number of cigarettes among current smokers (OR 3.4 for $\geq 35$ cigarettes/day). Risk increased in relation to duration of cigarette smoking up to 40 years of smoking (OR 2.4), and seems to decrease with time since cessation, reaching the level of never-smokers approximately 20 years after quitting [8].

\section{Nutrition}

Malnutrition is common in CP, which is aggravated because up to $50 \%$ of patients have increased resting energy expenditure, and its severity is a major predictive factor of complications and outcome. Although reducedfat diet may permit partial symptom control, fat content should be normal ( $30 \%$ of total energy intake) to prevent malnutrition. In fact, the European Society for Clinical Nutrition and Metabolism advocates a normal diet supplemented by pancreatic enzymes for the vast majority of patients [9]. Ten to $15 \%$ will require nutritional supplements and only $5 \%$ tube feeding. Deficiencies in vitamins $\mathrm{A}, \mathrm{D}, \mathrm{E}$, and $\mathrm{K}$ (secondary to steatorrhea), and in vitamin $\mathrm{B}_{12}$, calcium, magnesium, zinc, thiamine, and folic acid can also occur; so, they should be considered and supplemented if necessary $[9,10]$.

\section{Exocrine Pancreatic Insufficiency}

The role of PERT in patients with CP is inconclusive; a recent systematic review and meta-analysis of 17 randomized controlled trials demonstrated a statistically significant superiority of PERT versus placebo in terms of coefficient of fat absorption, coefficient of nitrogen absorption, reduced fecal fat and nitrogen excretion, fecal weight, and abdominal pain. The follow-up studies also demonstrated improvement of serum nutritional parameters, gastrointestinal symptoms, and quality of life. All these gains were achieved without significant adverse events [11]. Therefore, PERT is recommended in patients with significant steatorrhea ( $>15 \mathrm{~g} /$ day) and symptomatic steatorrhea (diarrhea, weight loss, or other signs of malnutrition) [12]. The benefit in treating asymptomatic patients with less severe steatorrhea (from 7.5 to $15 \mathrm{~g} /$ day) is not clear [13].

Typically, steatorrhea develops when the pancreatic lipase production falls to $<10 \%$ of normal. With the objective of controlling this, a minimal dosing of 25,000-50,000 IU of lipase per meal is required (providing approximately $10 \%$ of the physiologic pancreatic secretion). One cap- 
sule should be swallowed at the beginning of the meal (including small meals or snacks), and for major meals a second dosage should be administered during the meal to ensure an adequate release of enzymes throughout digestion. Patients who do not respond adequately to PERT should initiate a PPI, which is obligatory from the initiation of therapy in non-enteric-coated enzymes. Dose increase, if necessary, should be slow and accompanied by careful monitoring and symptom checking. In general, dosage should not exceed 10,000 IU lipase $/ \mathrm{kg}$ of body weight per day. Failure to improve steatorrhea after dose optimization and PPI should lead to investigate low patient compliance, intestinal bacterial overgrowth (present in one-third of patients) [14], intestinal infections, or other disorders associated with malabsorption [15].

There is a considerable variation in different countries in PERT dosage, enteric-coating, formulations (granules, tablets, microspheres, minimicrospheres, or capsules), kinetics of duodenal lipase release, and bioequivalence [16]. High-dose or enteric-coated enzymes showed a trend to greater effectiveness than low-dose or noncoated [11]. In Portugal, there are two formulations of entericcoated, gastroresistant capsules. These enteric-coated capsules of minimicrospheres contain amylase 8,000 U + lipase 10,000 $\mathrm{U}+$ protease $600 \mathrm{U}$, and amylase 18,000 $\mathrm{U}$ + lipase 25,000 U + protease 1,000 U, respectively, under the trademark of Kreon ${ }^{\circledR}$ and Kreon ${ }^{\circledR} 25,000$. There is one low-dose, nonenteric tablet formulation (amylase $6,000 \mathrm{U}+$ lipase $6,000 \mathrm{U}+$ protease $400 \mathrm{U}+$ dimeticone $80 \mathrm{mg}$ under the trademark of Pankreoflat ${ }^{\circledR}$ ) but has not an approved indication for the treatment of PEI [17].

The main objective of PERT is to avoid symptoms associated with PEI (diarrhea, weight loss, bloating) and normalize nutritional status. This should be assessed by evaluating body weight and weight loss, considering several factors such as nutrient intolerance, dietary intake and restrictions, symptoms of specific nutrient deficiencies, anthropometry, biochemical test, lymphocyte count, muscle function, and nutritional indexes. Alcohol or drug abuse should also be considered. The response to PERT can be objectively measured with ${ }^{13} \mathrm{C}$-mixed triglyceride breath test or the coefficient of fat absorption (CFA quantification). After symptom control, the chosen test should be repeated with increasing PERT doses until it attains a normal value. This approach is associated with a normalization of the body mass index and the nutritional status of patients. However, for most patients, symptoms and nutritional status are sufficient for monitoring response to treatment [13].

CPP Recommendations for Chronic Pancreatitis: Part II

\section{Endocrine Pancreatic Insufficiency}

Depending on the cohort, diabetes mellitus (DM) has been described in $26-80 \%$ of CP patients. In this context, $\mathrm{DM}$ is categorized as pancreatogenic diabetes (type 3), which is characterized by an absent pancreatic polypeptide response to mixed-nutrient ingestion [18]. Risk factors for DM3 in CP include longstanding duration of disease, prior partial pancreatectomy, and early onset of calcifications. Patients developing DM3 are likely to have PEI. The initial evaluation of CP patients includes fasting glucose and $\mathrm{HbAlc}$. The PancreasFest recommendations for diabetes advocate annual repetition of these tests [18]. The main endocrine defect in these patients is insulin deficiency but they also carry a greater risk of hypoglycemia when treated with insulin. In initial phases of disease, controlling mild hyperglycemia with oral hypoglycemic agents may be valid. In advanced disease, insulin is the only effective therapy, with dosing and regimen following the general recommendations for type 1 diabetes [18].

\section{Pain Management}

Pain is the most common symptom of $\mathrm{CP}$ and probably the most debilitating and challenging to treat. Most patients need some form of analgesia [19]. Significant worsening of pain or change of the usual characteristics or pattern usually implies a differential diagnosis to confirm that it is only an exacerbation of the disease and not another complication. After confirming pain due to CP, medical approach should begin with optimization of general measures and PERT. Subsequently, analgesic therapy should be escalated. Analgesics should be consumed before the meal, since a reduction in postprandial pain results in an increased food intake [9].

Pregabalin, tramadol, and morphine showed a potent analgesic effect in severe CP pain [20, 21]. Tramadol should be preferred as it interferes less with gastrointestinal function. Nonsteroidal anti-inflammatory drugs should preferentially not be used long-term due to their gastrointestinal adverse effects and because patients with alcoholic CP have a higher prevalence of peptic ulcers [22].

Pain processing by the central nervous system is abnormal in $\mathrm{CP}$ and resembles that observed in patients with neuropathic pain disorders. Therefore, strategies used for neuropathic pain should be transposed to CP. In this context, combined gabapentin and nortriptyline seems to be more efficacious than either drug given alone for neuropathic pain, and so, the use of this combination in patients who show a partial response to either drug given alone is recommended [23]. 
When pain occurs, it should be promptly dealt with by administering an oral analgesic in the following order: nonopioids (paracetamol); then, if necessary, mild opioids (tramadol) and finally, if unresponsive, strong opioids such as morphine. Adjuvants (such as nortriptyline) are extremely useful for controlling anxiety and fear associated with pain and can be initiated from the first step. In patients with frequent pain episodes, there should be a regular administration of analgesics to maintain pain freedom instead of an "on demand" strategy [24].

\section{Endoscopic Treatment}

Between 30 and $60 \%$ of patients with CP will ultimately require some type of endoscopic or surgical intervention for treatment. Endoscopic techniques are often used in combination with medical therapy and attempted before major operative interventions are pursued. However, regardless of the modality, they are often ineffective unless smoking and alcohol cessation is also achieved [25].

Intractable pain is the most common indication for endoscopic therapy, and treatment should be considered before patients become opiate-dependent. Endoscopic therapy should be considered as the first-line therapy for painful uncomplicated CP. Clinical response should be evaluated at 6-8 weeks; if unsatisfactory, patient's case should be reevaluated and surgical options should be considered, in particular in those with a predicted poor outcome following endoscopic therapy [26].

Endoscopic retrograde cholangiopancreatography can achieve MPD drainage by sphincterotomy of the major and/or minor papilla, short-term stent placement or pancreatic stone extraction, usually after fragmentation with extracorporeal shock wave lithotripsy (ESWL). The best candidates for successful treatment of painful CP are patients with distal obstruction of the MPD (single stone and/or single stricture in the head of the pancreas) and in the early stages of the disease [27].

\section{Pancreatic Duct Stones}

Pancreatic duct (PD) stones are a common complication of $\mathrm{CP}$ and produce pain by causing upstream dilation and ductal hypertension. They are seen in approximately $50 \%$ of patients with CP. Stones smaller than $5 \mathrm{~mm}$ without any evidence of MPD stricture can typically be removed by a Dormia basket or an extraction balloon after pancreatic sphincterotomy. Complete or partial pain relief after pancreatic sphincterotomy and mechanical stone extraction is seen in $50-77 \%$. These methods have some limitations in cases of stones greater than $5 \mathrm{~mm}$ in diameter, located upstream of an MPD stricture or impacted in the head of the pancreas, in which case adjunctive therapies or devices to fragment the stones may be needed $[28,29]$. The European Society of Gastrointestinal Endoscopy (ESGE) recommends ESWL as a first step, followed sometimes by endoscopic extraction of stone fragments in the presence of large $(>5 \mathrm{~mm})$ obstructive stone(s) located in the pancreatic head, and with ductal stenting in the presence of a dominant MPD stricture that induces a markedly dilated duct $[26,27]$. ESWL should be considered for patients with recurrent attacks of pancreatic pain, moderate to marked changes in the pancreatic ductal system and obstructing ductal stones. Factors associated with long-term pain relief are short disease duration, low frequency of pain attacks before treatment, complete ductal stone clearance, absence of MPD stricture, and discontinuation of alcohol and tobacco [27].

Early studies have shown that stone removal from the MPD leads to symptomatic improvement in a considerable proportion of CP patients $[28,30]$. However, the quality of evidence of reported results remains low in most of these retrospective observational nonrandomized studies. Only two randomized controlled trials compared endoscopic therapy and surgery, and both favored surgery. There were, however, several shortcomings, like low technical success rate and suboptimal procedures compared with previous studies. Endoscopic therapy should be an option since it is less invasive, being possible in patients with risk factors such as older age and comorbidities, and may reduce or delay the need for surgery. If clinical success can be obtained with $\leq 5$ endoscopic interventions, the patient will probably achieve long-term favorable outcome [27].

\section{PD Strictures}

MPD strictures are identified in many patients with CP [31]. Although in most cases they are benign, malignancy should be carefully excluded. Similar to PD stones, the aim of therapy is to decompress the ductal system by alleviating the narrowed segments.

The most commonly used approach involves pancreatic sphincterotomy, followed by dilation of the stricture, and placement of a PD stent [32]. The stent size should be at least as large as the MPD, in order to dilate the stenosis. A 10-Fr stent is less likely to be obstructed, although its placement is more difficult than a 5-Fr stent. The stents should be long enough to overpass the stenosis, and short enough to minimize ductal changes. 
A prospective study reported rapid symptomatic improvement following insertion of a pancreatic stent in nonoperable patients, although further interventions were frequently needed [33]. Removal of the obstruction of the MPD is effective for the treatment of pain in the short term, with reported success rates ranging from 37 to $94 \%$. A large study reported long-term pain relief in $84 \%$ of patients [31]. The same study showed that 79 and $97 \%$ of patients required new stent therapy for pain control within 1 and 2 years after the first procedure, respectively.

There is no consensus for how long stent therapy should be pursued, though some studies suggested that placement of a stent every 6 months achieves symptomatic control in the majority of patients. It should be noted that MPD stenting is associated with complications such as stent occlusion and stent migration. The ESGE recommends treating dominant MPD strictures by inserting a single 10-Fr plastic stent, with stent exchange planned within 1 year even in asymptomatic patients to prevent complications related to longstanding pancreatic stent occlusion [26]. Simultaneous placement of multiple, sideby-side, pancreatic stents could be applied more extensively, particularly in patients with MPD strictures persisting after 12 months of single plastic stenting. Even though preliminary studies suggest temporary placement of fully covered self-expandable metal stents (FCSEMS) is safe and allows resolution of MPD strictures plus pain relief in a majority of patients, it should only be performed in the setting of trials [26].

\section{Pancreatic Pseudocysts}

Pseudocysts develop in 20-40\% of patients with CP. Intraductal hypertension within the MPD or the rupture of a branching duct can lead to its formation. Drainage is indicated in pseudocysts that do not resolve spontaneously and are symptomatic, in particular if pain, infection, or evidence of obstruction occurs [34-36]. Pseudocyst drainage can be done percutaneously, endoscopically, or surgically. Compared with surgery, endoscopic drainage provides similar long-term results at a lower cost, shorter hospital stay, better quality of life during the first months following treatment, and a slightly lower procedure-related mortality.

When drainage is indicated, and before selecting the endoscopic approach, it is essential to accurately determine whether there is communication with the main or secondary PDs [37]. There are two different endoscopic strategies for managing pseudocysts. Transpapillary drainage involves directly inserting a stent through the
MPD into the collection, or trying to bridge the defect with a stent to prevent further leakage and redirect the flow of pancreatic juices back into the bowel. Transmural drainage consists of placement of double pigtail or self-expandable lumen-apposing metal stents (LAMS) from the stomach or the duodenum into the cyst cavity. Cystoduodenostomy should be preferred over cystogastrostomy if both routes are deemed equally feasible [37]. At least two double-pigtail plastic stents should be placed and should not be retrieved before cyst resolution as determined by cross-sectional imaging [26]. Whether drainage by plastic or LAMS leads to a better outcome or to fewer complications is still being debated [37]. Depending on the location, combined transsphincter, transmural, or transabdominal ultrasound and CT-guided or laparoscopic procedures may be necessary. Both approaches offer high rates of clinical success [38]. However, it should be pointed out that the technical success of transpapillary drainage is lower compared to the transmural approach. It should be reserved for small $(<5 \mathrm{~cm})$ communicating pseudocysts associated with a partial MPD disruption [39]. Since this approach may be associated with lower rates of bleeding and perforation, at the same time it allows for detection of MPD strictures and stones. However, the transpapillary approach may be burdened by the risks of acute pancreatitis, MPD scarring, or superinfection of the pseudocyst.

\section{Celiac Plexus Block}

The aim of celiac plexus block is to disrupt the transmission of afferent pain signals from the pancreas. It typically involves the injection of the celiac plexus with a local anesthetic mixed with a corticosteroid. EUS-guided approach is preferred over CT-guided approach since the former is associated with fewer side effects [40]. A prospective randomized study, comparing EUS versus CTguided celiac plexus block, reported pain relief in some $50 \%$ of patients in the EUS group, a percentage that was higher than that achieved when the procedure was performed under CT guidance $[40,41]$.

Several studies report the success rate as high as $95 \%$. However, and despite high rates of technical success, the efficacy in terms of long-term pain relief is disappointing. While short-term pain improvement is achieved in nearly half of patients, pain improvement 24 weeks after the procedure was reported in only $10 \%$ of patients. Given the low long-term success rates, EUS-guided celiac plexus block should be considered as a temporary measure. ESGE recommends considering celiac plexus block only 
as a second-line therapy in patients with limited options and reinforces that a EUS-guided approach should be preferred over a percutaneous one [26].

\section{Benign Biliary Strictures}

Benign biliary strictures are frequent in patients with $\mathrm{CP}$, with an estimated prevalence of 3-46\% [42]. Patients with biliary strictures may present with cholestasis, symptoms (pain, nausea, weight loss, jaundice, and pruritus), cholangitis, and biliary cirrhosis. Besides the presence of symptoms, indications for endoscopic intervention include the development of secondary biliary cirrhosis, common bile duct stones, worsening of the stricture based on increased proximal biliary ductal dilation, and persistent ( $>1$ month) jaundice or alkaline phosphatase elevation (2-3 times the upper limit of normal) [26].

Endoscopic management usually involves biliary stenting by endoscopic retrograde cholangiopancreatography. Balloon dilation alone is rarely performed, since strictures in this setting do not resolve easily. Placement of temporary (1-year) multiple, side-by-side, plastic biliary stents is recommended; an alternative approach is the placement of SEMS. Like stents in the MPD, stents in the bile duct need to be regularly exchanged to prevent occlusion and cholangitis. A suggested exchange interval for plastic stents is 3 months, whereas FCSEMS remain patent for 6 months or longer [37]. The rate of stricture resolution with plastic biliary stent placement is around $37 \%$ over 32 months, while SEMS patency is reported to range from 37 to $100 \%$ over a mean follow-up of 45 months [43]. A systematic review comparing the two approaches showed that clinical success was greater with SEMS (80\%) compared with single plastic stents (36\%) [44]. However, other studies have shown very high success rates with multiple plastic stents [45], and therefore, current guidelines favor this as the initial approach and do not yet support routine use of biliary SEMS for this indication [26]. However, FCSEMS seem to improve outcomes in case series and nonrandomized and randomized trials, with a stricture resolution rate of $76-93 \%$ and a recurrence rate of strictures of only $14-15 \%$ [37].

\section{Surgical Treatment}

For the most part of the 20th century, pancreatic resection surgery was associated with prohibitive morbidity and mortality, leading some authors to condemn this procedure as recently as in the 1970s [46]. At the beginning of the 1990s, with the advent of specialized centers in pancreatic surgery, there was a huge improvement in surgical outcomes $[47,48]$.

The history of CP surgery did not follow the same path as pancreatic resection surgery. Since resection results were so discouraging, surgeons pursued a different path in CP surgery, often preferring drainage to resection. Although surgery should be considered the best long-term option for pain management in CP, there is still no consensus about the best procedure. Drainage procedures like Partington and Rochelle pancreatojejunostomy [49] are a very safe option in patients with substantially dilated PD ( $>7 \mathrm{~mm}$ ), but this only occurs in less than a quarter of patients [50]. Furthermore, this approach has proven insufficient to deal with pain when the pancreatic head is not adequately drained [51].

When CP is associated with inflammatory mass of the head of the pancreas, pancreatic head resection, associated or not to a drainage procedure, is the technique of choice [52]. The supporters of duodenal preserving pancreatic head resection (DPPHR) argue that this procedure improves endocrine and exocrine functions and results in better postoperative quality of life, when compared to PDD $[53,54]$. It is not easy to say which DPPHR procedure is the best. The Berne technique is easier to perform than the Beger procedure, but there are no significant differences between them in relevant patient outcomes [55].

There is a consensus that PDD and distal pancreatic resections should be the treatment of choice in cases when malignancy is suspected [52]. Once CP features are present, the ability to differentiate between inflammation and pancreatic cancer is limited with current imaging or endoscopic ultrasound. When a suspicious pancreatic mass is present, even in the absence of pathologic confirmation, resection should be performed [52]. A prospective trial comparing PDD with DPPHR concluded that patients submitted to DPPHR have better quality of life scores [56]. Although both procedures significantly improve quality of life, the improvement may be more significant in DPPHR [57]. However, long-term results may not be significantly different in terms of quality of life, pain control, or other somatic parameters [58]. Because $\mathrm{CP}$ surgical caseload is small, a good argument in favor of PDD is that it is a much more frequently performed operation and it is what a hepato-pancreato-biliary surgeon is more comfortable with.

The goals of total pancreatectomy with islet cell autotransplant (TP-IAT) are to treat continuous pain, increase quality of life, and prevent pancreatic cancer [59]. Especially in North America, enthusiasts suggest that it has a definite role in the treatment of $\mathrm{CP}$, particularly in 
patients that present with parenchymal calcifications involving the whole organ with nondilated MPD, or in patients with refractory pain who have failed to respond to previous endoscopic and surgical treatment [60]. The PancreasFest recommendations for TP-IAT include intractable pain for which medical, endoscopic, or prior surgery have failed, but do not specify the time to propose surgery, only stating that patient and disease characteristics should be considered [61].

It is hard to determine the correct timing of surgery, but evidence is mounting that timely surgical intervention can at least delay the progression of pancreatic insufficiency $[52,57]$. In an international survey, $58 \%$ of the pancreatic specialists regard early surgical intervention (as soon as opioid analgesics are required) as superior to the step-up approach of medical treatment, followed by endoscopic interventions and surgery as a last resort [60]. Ahmed Ali et al. [62] state that surgery should be considered earlier in the course of CP, suggesting that it should be proposed within 3 years of symptom evolution. In the same sense Yang et al. [63] suggest that surgery within 26.5 months of diagnosis is associated with improved pain control. Several studies show that surgery in the later stages of CP results in central sensitization $[64,65]$, poor pain relief [63], and increased risk of cancer [66].

\section{Conclusion}

$\mathrm{CP}$ is a complex disease that should be treated by experienced teams of gastroenterologists, radiologists, surgeons, and nutritionists in a multidisciplinary environment. Medical treatment includes lifestyle modification, nutrition, exocrine and endocrine pancreatic insufficiency correction, and pain management. Up to $60 \%$ of pa- tients will ultimately require some type of endoscopic or surgical intervention for treatment. However, regardless of the modality, they are often ineffective unless smoking and alcohol cessation is also achieved. Surgery retains a major role in the treatment of $\mathrm{CP}$ patients with intractable chronic pain or suspected pancreatic mass. For other complications like biliary or gastroduodenal obstruction, pseudocyst drainage should be performed endoscopically.

\section{Disclosure Statement}

All authors disclose no personal conflicts of interest or financial relationships relevant to this publication.

\section{Funding Sources}

This study has not received any funding.

\section{Author Contributions}

Richard Azevedo and Ana Caldeira were responsible for literature review regarding etiology, natural history, and diagnosis; Teresa Antunes and Joana Rita Carvalho were responsible for literature review regarding clinical diagnosis and functional tests; João Bruno Soares and Pedro Oliveira were responsible for literature review regarding imaging modalities; Vítor Magno-Pereira and Pedro Moutinho-Ribeiro were responsible for literature review regarding medical treatment; Rodrigo Liberal and Eduardo Rodrigues-Pinto were responsible for literature review regarding endoscopic treatment; Tiago Bouça Machado and José Costa-Maia were responsible for literature review regarding surgical treatment. Results were discussed in two meetings of Clube Português do Pâncreas and approved by all members. All authors critically reviewed and approved the final manuscript.

\section{References}

1 Lankisch PG, Löhr-Happe A, Otto J, Creutzfeldt W. Natural course in chronic pancreatitis. Pain, exocrine and endocrine pancreatic insufficiency and prognosis of the disease. Digestion. 1993;54(3):148-55.

2 Gullo L, Barbara L, Labò G. Effect of cessation of alcohol use on the course of pancreatic dysfunction in alcoholic pancreatitis. Gastroenterology. 1988 Oct;95(4):1063-8.

3 Lankisch MR, Imoto M, Layer P, DiMagno EP. The effect of small amounts of alcohol on the clinical course of chronic pancreatitis. Mayo Clin Proc. 2001 Mar;76(3):242-51.
4 Cavallini G, Talamini G, Vaona B, Bovo P, Filippini M, Rigo L, et al. Effect of alcohol and smoking on pancreatic lithogenesis in the course of chronic pancreatitis. Pancreas. 1994 Jan;9(1):42-6.

5 Maisonneuve $\mathrm{P}$, Lowenfels AB, Müllhaupt B, Cavallini G, Lankisch PG, Andersen JR, et al. Cigarette smoking accelerates progression of alcoholic chronic pancreatitis. Gut. 2005 Apr; 54(4):510-4.

6 Rebours V, Vullierme MP, Hentic O, Maire F, Hammel P, Ruszniewski P, et al. Smoking and the course of recurrent acute and chronic alcoholic pancreatitis: a dose-dependent relationship. Pancreas. 2012 Nov;41(8):1219-24.
7 Coté GA, Yadav D, Slivka A, Hawes RH, Anderson MA, Burton FR, et al.; North American Pancreatitis Study Group. Alcohol and smoking as risk factors in an epidemiology study of patients with chronic pancreatitis. Clin Gastroenterol Hepatol. 2011 Mar;9(3): 266-73; quiz e27.

8 Bosetti C, Lucenteforte E, Silverman DT, Petersen G, Bracci PM, Ji BT, et al. Cigarette smoking and pancreatic cancer: an analysis from the International Pancreatic Cancer Case-Control Consortium (Panc4). Ann Oncol. 2012 Jul;23(7):1880-8. 
9 Meier R, Ockenga J, Pertkiewicz M, Pap A, Milinic N, Macfie J, et al.; DGEM (German Society for Nutritional Medicine); ESPEN (European Society for Parenteral and Enteral Nutrition). ESPEN Guidelines on Enteral Nutrition: pancreas. Clin Nutr. 2006 Apr;25(2): 275-84.

10 Sikkens EC, Cahen DL, Koch AD, Braat H, Poley JW, Kuipers EJ, et al. The prevalence of fat-soluble vitamin deficiencies and a decreased bone mass in patients with chronic pancreatitis. Pancreatology. 2013 May-Jun; 13(3):238-42.

11 de la Iglesia-García D, Huang W, Szatmary P, Baston-Rey I, Gonzalez-Lopez J, Prada-Ramallal G, et al.; NIHR Pancreas Biomedical Research Unit Patient Advisory Group. Efficacy of pancreatic enzyme replacement therapy in chronic pancreatitis: systematic review and meta-analysis. Gut. 2017 Aug;66(8): $1354-5$.

12 Löhr JM, Dominguez-Munoz E, Rosendahl J, Besselink M, Mayerle J, Lerch MM, et al.; HaPanEU/UEG Working Group. United European Gastroenterology evidence-based guidelines for the diagnosis and therapy of chronic pancreatitis (HaPanEU). United European Gastroenterol J. 2017 Mar;5(2):15399.

13 Domínguez-Muñoz JE. Chronic pancreatitis and persistent steatorrhea: what is the correct dose of enzymes? Clin Gastroenterol Hepatol. 2011 Jul;9(7):541-6.

14 Capurso G, Signoretti M, Archibugi L, Stigliano S, Delle Fave G. Systematic review and meta-analysis: small intestinal bacterial overgrowth in chronic pancreatitis. United European Gastroenterol J. 2016 Oct;4(5):697-705.

15 Keller J, Layer P. Human pancreatic exocrine response to nutrients in health and disease. Gut. 2005 Jul;54 Suppl 6:vi1-28.

16 Kuhn RJ, Eyting S, Henniges F, Potthoff A. In Vitro Comparison of Physical Parameters, Enzyme Activity, Acid Resistance, and $\mathrm{pH}$ Dissolution Characteristics of Enteric-Coated Pancreatic Enzyme Preparations: Implications for Clinical Variability and Pharmacy Substitution. J Pediatr Pharmacol Ther. 2007 Apr;12(2):115-28.

17 Autoridade Nacional do Medicamento e Produtos de Saúde I. Prontuário Terapêutico Infarmed. 2018. Available at: http://app10infarmedpt/prontuario/indexphp.

18 Rickels MR, Bellin M, Toledo FG, Robertson RP, Andersen DK, Chari ST, et al.; PancreasFest Recommendation Conference Participants. Detection, evaluation and treatment of diabetes mellitus in chronic pancreatitis: recommendations from PancreasFest 2012. Pancreatology. 2013 Jul-Aug;13(4):336-42.

19 Nusrat S, Yadav D, Bielefeldt K. Pain and opioid use in chronic pancreatitis. Pancreas. 2012 Mar;41(2):264-70.
20 Olesen SS, Bouwense SA, Wilder-Smith OH, van Goor H, Drewes AM. Pregabalin reduces pain in patients with chronic pancreatitis in a randomized, controlled trial. Gastroenterology. 2011 Aug;141(2):536-43.

21 Wilder-Smith CH, Hill L, Osler W, O'Keefe S. Effect of tramadol and morphine on pain and gastrointestinal motor function in patients with chronic pancreatitis. Dig Dis Sci. 1999 Jun;44(6):1107-16.

22 Chebli JM, de Souza AF, Gaburri PD, Bastos KV, Ribeiro TC, Filho RJ, et al. Prevalence and pathogenesis of duodenal ulcer in chronic alcoholic pancreatitis. J Clin Gastroenterol. 2002 Jul;35(1):71-4.

23 Gilron I, Bailey JM, Tu D, Holden RR, Jackson AC, Houlden RL. Nortriptyline and gabapentin, alone and in combination for neuropathic pain: a double-blind, randomised controlled crossover trial. Lancet. 2009 Oct; 374(9697):1252-61.

24 World Health Organization. Cancer pain relief: with a guide to opioid availability. 2 nd ed. Geneva: WHO; 1996

25 Riff BP, Chandrasekhara V. The Role of Endoscopic Retrograde Cholangiopancreatography in Management of Pancreatic Diseases. Gastroenterol Clin North Am. 2016 Mar; 45(1):45-65.

26 Dumonceau JM, Delhaye M, Tringali A, Dominguez-Munoz JE, Poley JW, Arvanitaki M, et al. Endoscopic treatment of chronic pancreatitis: European Society of Gastrointestinal Endoscopy (ESGE) Clinical Guideline. Endoscopy. 2012 Aug; 44(8): 784-800.

27 Drewes AM, Bouwense SA, Campbell CM, Ceyhan GO, Delhaye M, Demir IE, et al.; Working group for the International (IAP APA - JPS - EPC) Consensus Guidelines for Chronic Pancreatitis. Guidelines for the understanding and management of pain in chronic pancreatitis. Pancreatology. 2017 Sep - Oct; 17(5):720-31.

28 Sherman S, Lehman GA, Hawes RH, Ponich T, Miller LS, Cohen LB, et al. Pancreatic ductal stones: frequency of successful endoscopic removal and improvement in symptoms. Gastrointest Endosc. 1991 Sep-Oct;37(5): 511-7.

29 Smits ME, Rauws EA, Tytgat GN, Huibregtse K. Endoscopic treatment of pancreatic stones in patients with chronic pancreatitis. Gastrointest Endosc. 1996 Jun;43(6):556-60.

30 Dumonceau JM, Devière J, Le Moine O, Delhaye $M$, Vandermeeren A, Baize M, et al. Endoscopic pancreatic drainage in chronic pancreatitis associated with ductal stones: longterm results. Gastrointest Endosc. 1996 Jun; 43(6):547-55

31 Rösch T, Daniel S, Scholz M, Huibregtse K, Smits M, Schneider T, et al.; European Society of Gastrointestinal Endoscopy Research Group. Endoscopic treatment of chronic pancreatitis: a multicenter study of 1000 patients with long-term follow-up. Endoscopy. 2002 Oct; $34(10): 765-71$.
32 Smits ME, Badiga SM, Rauws EA, Tytgat GN Huibregtse K. Long-term results of pancreatic stents in chronic pancreatitis. Gastrointest Endosc. 1995 Nov;42(5):461-7.

33 Treacy PJ, Worthley CS. Pancreatic stents in the management of chronic pancreatitis. Aust N Z J Surg. 1996 Apr;66(4):210-3.

34 Adler DG, Lichtenstein D, Baron TH, Davila R, Egan JV, Gan SL, et al. The role of endoscopy in patients with chronic pancreatitis. Gastrointest Endosc. 2006 Jun;63(7):933-7.

35 Kahaleh M, Shami VM, Conaway MR, Tokar J, Rockoff T, De La Rue SA, et al. Endoscopic ultrasound drainage of pancreatic pseudocyst: a prospective comparison with conventional endoscopic drainage. Endoscopy. 2006 Apr;38(4):355-9.

36 Krüger M, Schneider AS, Manns MP, Meier PN. Endoscopic management of pancreatic pseudocysts or abscesses after an EUS-guided 1-step procedure for initial access. Gastrointest Endosc. 2006 Mar;63(3):409-16.

37 Kleeff J, Whitcomb DC, Shimosegawa T, Esposito I, Lerch MM, Gress T, et al. Chronic pancreatitis. Nat Rev Dis Primers. 2017 Sep;3: 17060.

38 Shrode CW, Macdonough P, Gaidhane M, Northup PG, Sauer B, Ku J, et al. Multimodality endoscopic treatment of pancreatic duct disruption with stenting and pseudocyst drainage: how efficacious is it? Dig Liver Dis. 2013 Feb;45(2):129-33.

39 Varadarajulu S, Rana SS, Bhasin DK. Endoscopic therapy for pancreatic duct leaks and disruptions. Gastrointest Endosc Clin N Am. 2013 Oct;23(4):863-92.

40 Gress F, Schmitt C, Sherman S, Ikenberry S, Lehman G. A prospective randomized comparison of endoscopic ultrasound- and computed tomography-guided celiac plexus block for managing chronic pancreatitis pain. Am J Gastroenterol. 1999 Apr;94(4):900-5.

41 Gress F, Schmitt C, Sherman S, Ciaccia D, Ikenberry S, Lehman G. Endoscopic ultrasound-guided celiac plexus block for managing abdominal pain associated with chronic pancreatitis: a prospective single center experience. Am J Gastroenterol. 2001 Feb;96(2): 409-16.

42 Vijungco JD, Prinz RA. Management of biliary and duodenal complications of chronic pancreatitis. World J Surg. 2003 Nov;27(11): 1258-70.

43 Arslanlar S, Jain R. Benign biliary strictures related to chronic pancreatitis: balloons, stents, or surgery. Curr Treat Options Gastroenterol. 2007 Oct;10(5):369-75.

44 van Boeckel PG, Vleggaar FP, Siersema PD. Plastic or metal stents for benign extrahepatic biliary strictures: a systematic review. BMC Gastroenterol. 2009 Dec;9(1):96.

45 Catalano MF, Linder JD, George S, Alcocer E, Geenen JE. Treatment of symptomatic distal common bile duct stenosis secondary to chronic pancreatitis: comparison of single vs. multiple simultaneous stents. Gastrointest Endosc. 2004 Dec;60(6):945-52. 
46 Crile G Jr. The advantages of bypass operations over radical pancreatoduodenectomy in the treatment of pancreatic carcinoma. Surg Gynecol Obstet. 1970 Jun;130(6):1049-53.

47 Cameron JL, Pitt HA, Yeo CJ, Lillemoe KD, Kaufman HS, Coleman J. One hundred and forty-five consecutive pancreaticoduodenectomies without mortality. Ann Surg. 1993; 217(5):430-5; discussion 435-8.

48 Trede M, Schwall G, Saeger HD. Survival after pancreatoduodenectomy. 118 consecutive resections without an operative mortality. Ann Surg. 1990 Apr;211(4):447-58.

49 Partington PF, Rochelle RE. Modified Puestow procedure for retrograde drainage of the pancreatic duct. Ann Surg. 1960 Dec; 152(6):1037-43.

50 Büchler MW, Warshaw AL. Resection versus drainage in treatment of chronic pancreatitis. Gastroenterology. 2008 May;134(5):1605-7.

51 Delhaye M, Van Steenbergen W, Cesmeli E, Pelckmans P, Putzeys V, Roeyen G, et al. Belgian consensus on chronic pancreatitis in adults and children: statements on diagnosis and nutritional, medical, and surgical treatment. Acta Gastroenterol Belg. 2014 Mar; 77(1):47-65.

52 Hoffmeister A, Mayerle J, Beglinger C, Büchler MW, Bufler P, Dathe K, et al.; members of the guideline committee. English language version of the S3-consensus guidelines on chronic pancreatitis: Definition, aetiology, diagnostic examinations, medical, endoscopic and surgical management of chronic pancreatitis. Z Gastroenterol. 2015 Dec;53(12): 1447-95.
53 Klempa I, Spatny M, Menzel J, Baca I, Nustede R, Stöckmann F, et al. [Pancreatic function and quality of life after resection of the head of the pancreas in chronic pancreatitis. A prospective, randomized comparative study after duodenum preserving resection of the head of the pancreas versus Whipple's operation]. Chirurg. 1995 Apr;66(4):350-9.

54 Bloechle C, Izbicki JR, Knoefel WT, Kuechler $\mathrm{T}$, Broelsch CE. Quality of life in chronic pancreatitis-results after duodenum-preserving resection of the head of the pancreas. Pancreas. $1995 \mathrm{Jul} ; 11(1): 77-85$.

55 Plagemann S, Welte M, Izbicki JR, Bachmann K. Surgical Treatment for Chronic Pancreatitis: Past, Present, and Future. Gastroenterol Res Pract. 2017;2017:8418372.

56 Witzigmann H, Max D, Uhlmann D, Geissler F, Ludwig S, Schwarz R, et al. Quality of life in chronic pancreatitis: a prospective trial comparing classical whipple procedure and duodenum-preserving pancreatic head resection. J Gastrointest Surg. 2002 Mar-Apr;6(2):1739.

57 Belina F, Fronek J, Ryska M. Duodenopancreatectomy versus duodenum-preserving pancreatic head excision for chronic pancreatitis. Pancreatology. 2005;5(6):547-52.

58 Strate T, Bachmann K, Busch P, Mann O, Schneider C, Bruhn JP, et al. Resection vs drainage in treatment of chronic pancreatitis: long-term results of a randomized trial. Gastroenterology. 2008 May;134(5):1406-11.

59 Conwell DL, Lee LS, Yadav D, Longnecker DS, Miller FH, Mortele KJ, et al. American Pancreatic Association Practice Guidelines in Chronic Pancreatitis: evidence-based report on diagnostic guidelines. Pancreas. 2014 Nov; 43(8):1143-62.

60 Issa Y, van Santvoort HC, Fockens P, Besselink MG, Bollen TL, Bruno MJ, et al.; Collaborators. Diagnosis and treatment in chronic pancreatitis: an international survey and case vignette study. HPB (Oxford). 2017 Nov; 19(11):978-85.
61 Bellin MD, Freeman ML, Gelrud A, Slivka A, Clavel A, Humar A, et al. Total pancreatectomy and islet autotransplantation in chronic pancreatitis: recommendations from PancreasFest. Pancreatology. 2014 Jan-Feb;14(1): 27-35.

62 Ahmed Ali U, Nieuwenhuijs VB, van Eijck $\mathrm{CH}$, Gooszen HG, van Dam RM, Busch OR, et al.; Dutch Pancreatitis Study Group. Clinical outcome in relation to timing of surgery in chronic pancreatitis: a nomogram to predict pain relief. Arch Surg. 2012 Oct;147(10):92532.

63 Yang CJ, Bliss LA, Freedman SD, Sheth S, Vollmer CM, Ng SC, et al. Surgery for chronic pancreatitis: the role of early surgery in pain management. Pancreas. 2015 Jul;44(5):81923.

64 Wilson GC, Sutton JM, Smith MT, Schmulewitz N, Salehi M, Choe KA, et al. Completion pancreatectomy and islet cell autotransplantation as salvage therapy for patients failing previous operative interventions for chronic pancreatitis. Surgery. 2015 Oct;158(4):872-8; discussion 879-80.

65 Bouwense SA, Olesen SS, Drewes AM, Frøkjær JB, van Goor H, Wilder-Smith $\mathrm{OH}$. Is altered central pain processing related to disease stage in chronic pancreatitis patients with pain? An exploratory study. PLoS One. 2013;8(2):e55460.

66 Lowenfels AB, Maisonneuve P, Cavallini G, Ammann RW, Lankisch PG, Andersen JR, et al.; International Pancreatitis Study Group. Pancreatitis and the risk of pancreatic cancer. N Engl J Med. 1993 May;328(20):1433-7. 